\title{
On the Redistribution of Bending Moments in Two-Span RC Beams and Slabs Exposed to Fire
}

\author{
Robert Kowalski and Marek Urbański \\ Faculty of Civil Engineering, Warsaw University of Technology, Warsaw 00-637, Poland
}

\begin{abstract}
This paper shows consideration of decrease in cross-section stiffness in commonly used in practice RC (reinforced concrete) beams and slabs in cases when only reinforcing bars or only concrete compressed zone, which is subjected to fire. Analyses were based on: (1) standard fire curve [EN 1991-1-2]; (2) $500{ }^{\circ} \mathrm{C}$ isotherm method assumptions [EN 1992-1-2]; (3) mechanical properties of reinforcing steel heated up to high temperature. Afterwards, based on estimated decrease of cross-sections stiffness, the redistribution of bending moments was calculated in some cases of two-span RC beams and slabs subjected to fire from their bottom face. Due to the bending moment redistribution, one could expect a reduction of bending moments in span cross-sections and an increase of support bending moment. As a result of this phenomenon, the ultimate limit state of the structural multi span elements might occur after shorter fire duration than it could be expected when redistribution of bending moments is neglected.
\end{abstract}

Key words: Concrete, cross-section, fire design, stiffness.

\section{Introduction}

When reinforced concrete elements are exposed to fire, contraction of concrete and elongation of reinforcing bars can be much larger than found at room temperature [1-3]. This results in a significant reduction in cross-section stiffness, leading to high deformations (deflections) of the elements. Sometimes the large deflection bending elements can be prevented by the formation of a static scheme of secondary structures (e.g., if the bending elements lean against partition walls) [4].

In predicting the fire resistance of roof elements, the worst fire scenario occurs when fire works from the bottom of the elements. In this case, in the span cross-sections is heated only reinforcement, and in cross-sections of the support only a compressed zone of concrete. Relative changes in the stiffness of the support and span cross-sections may result in the

Corresponding author: Robert Kowalski, Ph.D., D.Sc., associate professor, research fields: building structures, behavior of RC structures in fire and on influence of high temperature on mechanical properties of concrete and reinforcing steel. E-mail: r.kowalski@il.pw.edu.pl. redistribution of bending moments under fire conditions.

The study analyzed computationally, how changes in stiffness encountered in the practice of slabs and reinforced concrete beams cross-sections exposed to fire only on the tensile reinforcement, or only from the compression zone of concrete. Then, using the two-span elements, has been determined what may be the impact of relative variation of stiffness of the sections to redistribution of bending moments and the projected capacity fire of elements.

It should also be noted that in case of fires in complex public or industrial buildings, in practice very rarely the structure is exposed to intense heat from all sides. Most parts (elements) are heated only from the zone of compression, or only from the expanded zone. Competent forecasting of changes in the stiffness of individual elements (cross-sections) and the appropriate redistribution of internal forces forecasting may be crucial during a global analysis of complex reinforced concrete structures under fire conditions. 


\section{Stiffness of Cross-Section RC Slabs under Fire Conditions}

\subsection{Assumptions}

Examined four cases two-span slabs of the span, thickness and reinforcement were chosen so that the conditions were fulfilled, the limit state bearing capacity and usability [5]. Adopted variable load $q_{k}=$ $5.00 \mathrm{kN} / \mathrm{m}^{2}$, which corresponds to the category of use such as $\mathrm{C}$ or D $[6,7]$ and a permanent load $\left(g_{k}\right)$, which is the sum of the weight of its own slabs and the value of $1.25 \mathrm{kN} / \mathrm{m}^{2}$. For the calculation of the ULS (ultimate limit state), it has adopted a more unfavourable combination of loads specified by the formulas [6] and has been adopted:

$$
\begin{aligned}
& p=\gamma_{G \text {, sup }} \cdot g_{k}+\gamma_{Q} \cdot \psi_{0} \cdot q_{k} \\
& p=\xi \cdot \gamma_{G \text {, sup }} \cdot g_{k}+\gamma_{Q} \cdot q_{k}
\end{aligned}
$$

For the calculation of SLS (serviceability limit state-deflection), it assumed a quasi-permanent combination of loads according to the formula:

$$
p_{q p}=g_{k}+\psi_{2} \cdot q_{k}
$$

In these formulas:

$\gamma_{G, \text { sup }}$ - partial safety factor for permanent loads, $\gamma_{G, \text { sup }}=1.35$;

$\gamma_{Q}$-the partial coefficient for the effects variable, $\gamma_{Q}$ $=1.50$;

$\psi_{0}$ - the ratio of the value of combining the variable effects, $\psi_{0}=0.7$;

$\xi$-a reduction factor, $\xi=0.85$;

$\psi_{2}$ - the ratio of the quasi-permanent value of variable loads, $\psi_{2}=0.6$.

It is assumed that all slabs are made of C30/37 concrete, reinforced with steel of characteristic yield strength $f_{y k}=500 \mathrm{MPa}$. Distance from the edge of the axis of cross-section bars is $30 \mathrm{~mm}$. Table 1 shows the most important information about the slabs.

It should be noted that the combination of loads determined by the Eq. (3) is also suitable for the analysis of fire conditions $[6,8,9]$. Given in Table 1, the coefficient $\eta$ is the ratio of bending moment in fire condition against the bending moment adopted to check the ULS.

Stiffness of slabs cross-sections in the fire conditions has been determined based on assumptions of the $500{ }^{\circ} \mathrm{C}$-isotherm method, recommended in Ref. [9] to calculate the bearing capacity of reinforced concrete elements exposed to standard fire [8]. This method assumes that the concrete in the outer part of cross-section, where the temperature exceeds $500{ }^{\circ} \mathrm{C}$, is completely destroyed. In the rest, the inside of the section it is assumed that the strength of concrete is the same as at room temperature. The mechanical properties of reinforcement have been accepted depending on its temperature, regardless of whether the bars are located inside or outside the area limited by the position of $500{ }^{\circ} \mathrm{C}$-isotherm.

In the case of heating the tension zone (span cross-section), it was considered as a cross-section of unchanged dimensions, taking into account only increase the elongation of reinforcement. In the case of the compression zone heating, the cross-section of reduced dimensions and unchanged mechanical characteristics of reinforcement has been examined. The following presents the used calculation procedure.

\subsection{The Procedure for Calculating Cross-Sectional Span Stiffness (Heated Reinforcement)}

The first calculation was performed for the duration of the fire $t=0 \mathrm{~min}$. The data used for the calculation are

\begin{tabular}{|c|c|c|c|c|c|c|c|c|c|}
\hline \multirow{2}{*}{$\begin{array}{l}\text { Length } \\
\text { (m) }\end{array}$} & \multirow{2}{*}{$\begin{array}{l}\text { High } \\
(\mathrm{cm})\end{array}$} & \multicolumn{2}{|c|}{$\operatorname{Load}\left(\mathrm{kN} / \mathrm{m}^{2}\right)$} & \multicolumn{3}{|c|}{ Span reinforcement } & \multicolumn{3}{|c|}{ Support reinforcement } \\
\hline & & ULS & SLS & $\eta$ & $A_{s}$ & $\rho(\%)$ & $\eta$ & $A_{s}$ & $\rho(\%)$ \\
\hline 7.20 & 25 & 16.13 & 10.50 & 0.61 & $\varnothing 10 / 100$ & 0.36 & 0.65 & $ø 12 / 140$ & 0.54 \\
\hline 6.00 & 20 & 14.69 & 9.25 & 0.59 & $\varnothing 10 / 120$ & 0.38 & 0.63 & $\varnothing 16 / 210$ & 0.56 \\
\hline 4.80 & 16 & 13.54 & 8.25 & 0.57 & $\varnothing 10 / 150$ & 0.40 & 0.61 & $\varnothing 12 / 140$ & 0.58 \\
\hline 3.60 & 12 & 12.39 & 7.25 & 0.55 & $\varnothing 8 / 130$ & 0.42 & 0.59 & $\varnothing 8 / 90$ & 0.62 \\
\hline
\end{tabular}
suitable for the calculated accidental situation of fire:

Table 1 Key parameters of considered slabs. 
- Bending moment calculated for the load combinations according to Eq. (3) (Table 1);

- Mechanical characteristics of concrete and reinforcing steel;

- Concrete creep coefficient of at $\varphi=2.09 \div 2.30$, $E_{c, \text { eff }}=10.63 \div 9.94 \mathrm{GPa}$.

But it does not include the impact of high temperatures.

Stiffness of the cross section was calculated by the formula [5]:

$$
B=\frac{1}{\frac{1-\zeta}{B_{I}}+\frac{\zeta}{B_{I I}}}
$$

in which:

$B_{\mathrm{I}}$ - stiffness is determined on the assumption that the cross-section is not cracked;

$B_{\mathrm{II}}$-stiffness is determined on the assumption that the cross-section is fully cracked;

(a)

$$
\begin{aligned}
& \text { Position of } 500^{\circ} \mathrm{C} \text {-isotherm: } \\
& \text { Duration of standard fire: } \\
& \mathrm{t}=30 \mathrm{~min} .-\mathrm{a}_{500}=1.0 \mathrm{~cm} \\
& \mathrm{t}=60 \mathrm{~min} .-\mathrm{a}_{500}=2.0 \mathrm{~cm} \\
& \mathrm{t}=90 \mathrm{~min} .-\mathrm{a}_{500}=3.0 \mathrm{~cm} \\
& \mathrm{t}=120 \mathrm{~min} .-\mathrm{a}_{500}=3.5 \mathrm{~cm} \\
& \mathrm{t}=180 \mathrm{~min} .-\mathrm{a}_{500}=5.0 \mathrm{~cm} \\
& \mathrm{t}=240 \mathrm{~min} .-\mathrm{a}_{500}=6.0 \mathrm{~cm}
\end{aligned}
$$

$\xi$-is a factor related to the impact of tension stiffening.

In the next step - the calculations for the duration of the fire, $t=30 \mathrm{~min}$.

Reinforcement temperature $\left(\theta_{S}\right)$ is estimated on the basis of Fig. 1a [10]. They are the guidelines for a simplified prediction of reinforcement temperature and isotherms of $500{ }^{\circ} \mathrm{C}$ position in cross-sections of $\mathrm{RC}$ slabs. For the duration of the fire, $t=30 \mathrm{~min}$ obtained $\theta_{s}$ $=220{ }^{\circ} \mathrm{C}$.

Then the total elongation of reinforcement $\left(\varepsilon_{s, t o t}\right)$ has been estimated. In this regard, graphs given in Fig. 2 have been used [11]. They represent the stress-strain relationship developed on the basis of Ref. [9] of the free thermal elongation of steel.

The vertical axis shows stress in the reinforcement calculated for the previously considered the duration of

(b)

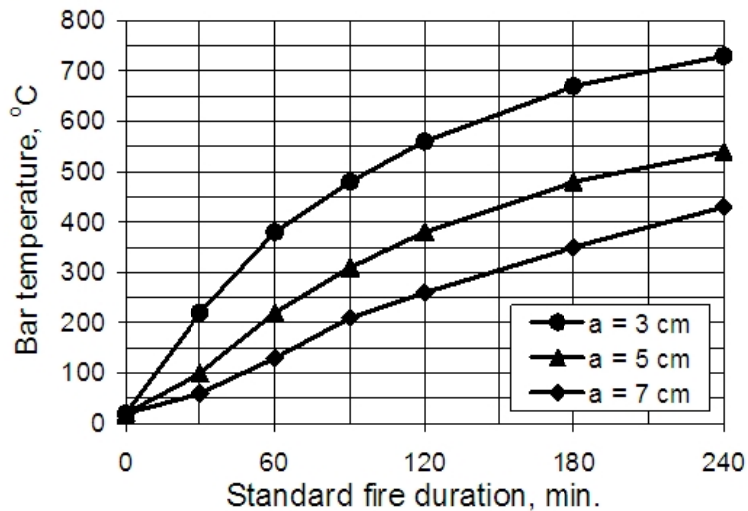

Fig. 1 Recommendation for a simplified evaluation of the temperature in the bars when using the " $500{ }^{\circ} \mathrm{C}$-isotherm method": (a) $a_{500}$-position of the $500{ }^{\circ} \mathrm{C}$-isotherm; (b) the temperature of the reinforcing bars [10].

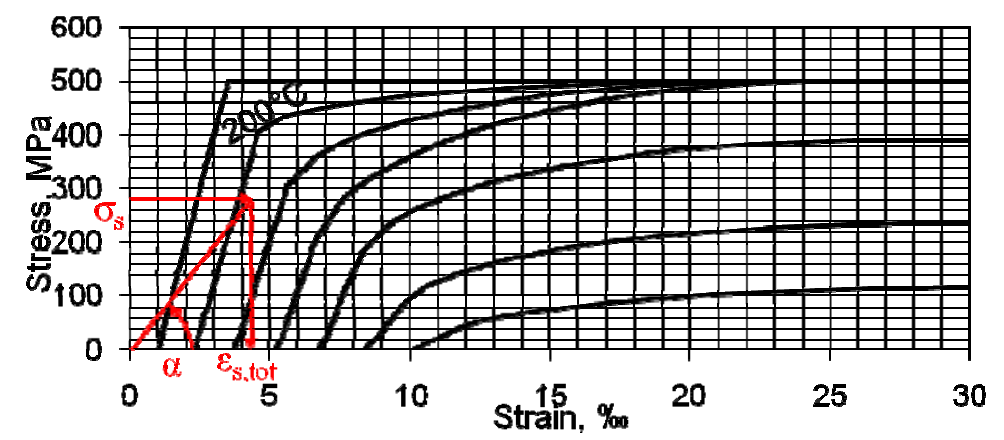

Fig. 2 The stress-strain relationship (included steel free thermal elongation) for hot-rolled reinforcing steel $\left(f_{y k}=500 \mathrm{MPa}\right)$ at high temperatures [11], looking from the left side of the figure the successive lines refer to the temperature $100{ }^{\circ} \mathrm{C}, 200{ }^{\circ} \mathrm{C}$, $300{ }^{\circ} \mathrm{C}, 400{ }^{\circ} \mathrm{C}, 500{ }^{\circ} \mathrm{C}, 600{ }^{\circ} \mathrm{C}$, and $700{ }^{\circ} \mathrm{C}$, respectively. 
the fire. The horizontal axis is for the full extension of the reinforcement, depending on the temperature. In the case of slabs with spans of $7.2 \mathrm{~m}$ tension in the reinforcement at the beginning of the fire was $\sigma_{s}=280$ $\mathrm{MPa}$, temperature of the reinforcement $\theta_{s}=220{ }^{\circ} \mathrm{C}$, and elongation of reinforcement read $\varepsilon_{s, t o t}=4.18 \%$ (in fact, instead of charting analytical materials have been used for their preparation).

Resultant modulus of elasticity of steel was calculated by the formula:

$$
\tan \alpha=E_{s, f i}=\frac{\sigma_{s}(t=0)}{\varepsilon_{s, t o t}}
$$

Taking into account the impact of the elastic modulus defined by Eq. (5) cross-sectional stiffness $\left(B_{f i}\right)$ has been calculated, according to Eq. (4), and the adjusted value of the stresses in the reinforcement $\left(\sigma_{s}\right)$ has been used. The next step calculation procedure described above was repeated for successive durations of fire. Calculations have been done to apply in the calculated load bearing capacity. Cross-section load bearing capacity was calculated according to $500{ }^{\circ} \mathrm{C}$-isotherm method, depending on the calculated tensile strength of steel $\left(f_{s y}, \theta=k_{s, \theta} f_{y k}\right)$ defined by Fig. 3 . Table 2 presents the main results of the calculations.

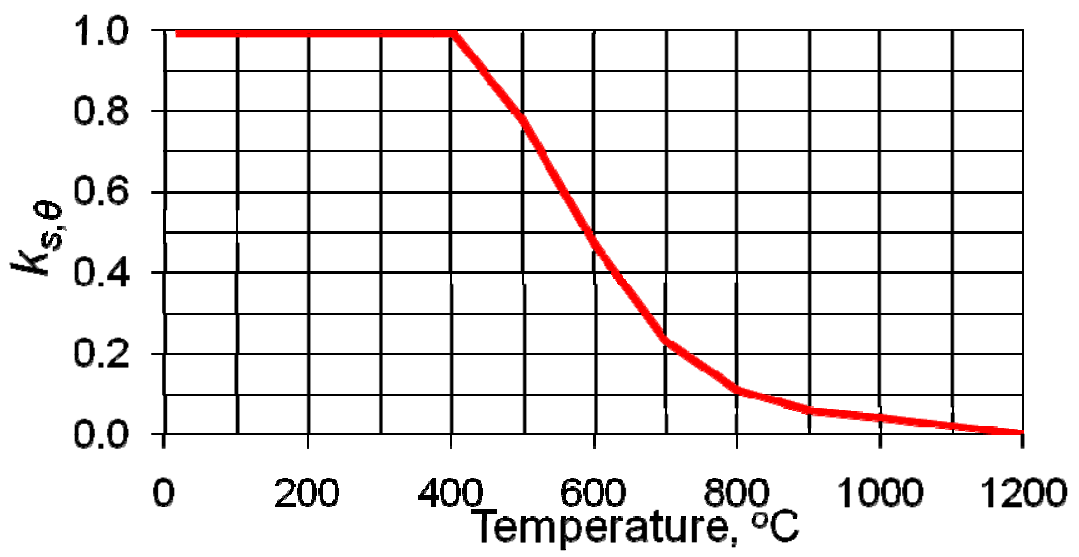

Fig. 3 The reducing factor of the yield strength of reinforcing steel [9].

Table 2 Key results of the calculations.

\begin{tabular}{ccllllllll}
\hline \multicolumn{2}{l}{ (a) A span slab $7.2 \mathrm{~m}(h=25 \mathrm{~cm})$} \\
\hline$t(\mathrm{~min})$ & $\theta_{s}\left({ }^{\circ} \mathrm{C}\right)$ & $\sigma_{s}(\mathrm{MPa})$ & $f_{s y, \Theta}(\mathrm{MPa})$ & $\varepsilon_{s, t o t}(\%)$ & $E_{s, f i}(\mathrm{GPa})$ & $B_{I}\left(\mathrm{kNm}^{2}\right)$ & $B_{I I}\left(\mathrm{kNm}^{2}\right)$ & $B_{f i}\left(\mathrm{kNm}^{2}\right)$ & $B_{f i} / B_{f i}(t=0)$ \\
\hline 0 & 20 & 280 & 500 & 1.40 & 200.0 & 15,175 & 4,742 & 5,691 & 1.00 \\
30 & 220 & 268 & 500 & 4.18 & 67.0 & 12,905 & 1,925 & 2,343 & 0.41 \\
60 & 380 & 264 & 500 & 6.91 & 38.8 & 11,106 & 1,192 & 1,410 & 0.25 \\
90 & 480 & 262 & 412 & 9.52 & 27.7 & 10,075 & 881 & 1,024 & 0.18 \\
120 & 560 & 259 & 297 & 17.05 & 15.4 & 8,953 & 511 & 584 & 0.10 \\
133 & 600 & 257 & 260 & 26.59 & 9.7 & 7,515 & 333 & 370 & 0.07 \\
\hline (b) A span slab $6.0 \mathrm{~m}(\mathrm{~h}=20 \mathrm{~cm})$ & & & & & & & \\
\hline$t$ (min) & $\theta_{s}\left({ }^{\circ} \mathrm{C}\right)$ & $\sigma_{s}(\mathrm{MPa})$ & $f_{s y, \Theta}(\mathrm{MPa})$ & $\varepsilon_{s, t o t}(\%)$ & $E_{s, f i}(\mathrm{GPa})$ & $B_{I}\left(\mathrm{kNm}^{2}\right)$ & $B_{I I}\left(\mathrm{kNm}^{2}\right)$ & $B_{f i}\left(\mathrm{kNm}^{2}\right)$ & $B_{f i} / B_{f i}(t=0)$ \\
\hline 0 & 20 & 270 & 500 & 1.35 & 200.0 & 7,689 & 2,319 & 2,829 & 1.00 \\
30 & 220 & 258 & 500 & 4.13 & 65.0 & 6,403 & 931 & 1,140 & 0.40 \\
60 & 380 & 255 & 500 & 6.78 & 38.1 & 5,322 & 580 & 683 & 0.24 \\
90 & 480 & 253 & 412 & 9.22 & 27.6 & 4,710 & 434 & 499 & 0.18 \\
120 & 560 & 250 & 297 & 15.91 & 15.9 & 4,057 & 261 & 294 & 0.10 \\
136 & 590 & 248 & 250 & 28.18 & 8.9 & 3,811 & 151 & 169 & 0.06 \\
\hline
\end{tabular}


(Table 2 continued)

\begin{tabular}{|c|c|c|c|c|c|c|c|c|c|}
\hline \multicolumn{10}{|c|}{ (c) A span slab $4.8 \mathrm{~m}(\mathrm{~h}=16 \mathrm{~cm})$} \\
\hline$t(\min )$ & $\theta_{s}\left({ }^{\circ} \mathrm{C}\right)$ & $\sigma_{s}(\mathrm{MPa})$ & $f_{s y, \Theta}(\mathrm{MPa})$ & $\varepsilon_{s, t o t}(\%)$ & $E_{s, f i}(\mathrm{GPa})$ & $B_{I}\left(\mathrm{kNm}^{2}\right)$ & $B_{I I}\left(\mathrm{kNm}^{2}\right)$ & $B_{f i}\left(\mathrm{kNm}^{2}\right)$ & $B_{f i} / B_{f i}(t=0)$ \\
\hline 0 & 20 & 256 & 500 & 1.28 & 200.0 & 3,874 & 1,073 & 1,390 & 1.00 \\
\hline 30 & 220 & 245 & 500 & 4.05 & 63.0 & 3,145 & 420 & 537 & 0.39 \\
\hline 60 & 380 & 241 & 500 & 6.62 & 37.0 & 2,499 & 262 & 315 & 0.23 \\
\hline 90 & 480 & 239 & 412 & 8.84 & 27.2 & 2,140 & 200 & 231 & 0.17 \\
\hline 120 & 560 & 237 & 297 & 14.47 & 16.5 & 1,769 & 126 & 142 & 0.10 \\
\hline 142 & 598 & 235 & 237 & 27.85 & 8.5 & 1,590 & 68 & 75 & 0.05 \\
\hline \multicolumn{10}{|c|}{ (d) A span slab $3.6 \mathrm{~m}(\mathrm{~h}=12 \mathrm{~cm})$} \\
\hline$t(\min )$ & $\theta_{s}\left({ }^{\circ} \mathrm{C}\right)$ & $\sigma_{s}(\mathrm{MPa})$ & $f_{s y, \Theta}(\mathrm{MPa})$ & $\varepsilon_{s, t o t}(\%)$ & $E_{s, f i}(\mathrm{GPa})$ & $B_{I}\left(\mathrm{kNm}^{2}\right)$ & $B_{I I}\left(\mathrm{kNm}^{2}\right)$ & $B_{f i}\left(\mathrm{kNm}^{2}\right)$ & $B_{f i} / B_{f i}(t=0)$ \\
\hline 0 & 20 & 257 & 500 & 1.29 & 200.0 & 1,493 & 364 & 518 & 1.00 \\
\hline 30 & 220 & 245 & 500 & 4.05 & 63.4 & 1,159 & 145 & 193 & 0.37 \\
\hline 60 & 380 & 241 & 500 & 6.63 & 37.0 & 849 & 90 & 109 & 0.21 \\
\hline 90 & 480 & 240 & 412 & 8.85 & 27.3 & 684 & 69 & 79 & 0.15 \\
\hline 120 & 560 & 237 & 297 & 14.49 & 16.5 & 522 & 44 & 48 & 0.09 \\
\hline 140 & 596 & 235 & 240 & 24.86 & 9.5 & 332 & 26 & 28 & 0.04 \\
\hline
\end{tabular}

2.3 The Procedure for Calculating the Stiffness of the Support Section (Heated Compressed Zone of Concrete)

The first calculation was performed for the beginning of the fire ( $t=0 \mathrm{~min})$, assuming the data presented in Section 2.2. Then, based on Eq. (4) calculated cross-sectional stiffness $\left(B_{f i}\right)$ for successive durations of fire. According to the assumptions of the $500{ }^{\circ} \mathrm{C}$-isotherm method [9] dealt with a reduced cross-sectional height (Fig. 4), and unchanged mechanical characteristics of reinforcement $\left(E_{s}=200\right.$ $\left.\mathrm{GPa}, f_{y k}=500 \mathrm{MPa}\right)$ and concrete $\left(E_{c, \text { eff }}=10.63\right.$, $10.39,10.21,9.91 \mathrm{GPa}$ for $\mathrm{h}=25,20,16,12 \mathrm{~cm}$, respectively). Location of $500{ }^{\circ} \mathrm{C}$ isotherms $\left(a_{500}\right)$ in cross-section was estimated on the basis of Fig. 1a [10]. The slabs with a thickness of 25 and $20 \mathrm{~cm}$ (range from $7.2 \mathrm{~m}$ to $6.0 \mathrm{~m}$ ) calculated load bearing capacity of cross-section is not exhausted even after 240 min of fire duration. The slabs of smaller thickness calculations were carried out until the calculated load bearing capacity. Table 3 presents the main results of the calculations.
2.4 Analysis of Stiffness Reduction in Cross-Section of Slabs

Fig. 5 shows the ratio of the stiffness of the cross section, calculated for successive durations of the fire against the initial stiffness $\left(B_{f i} / B_{f i}(t=0)\right)$, for span and support cross-sections (Tables 2 and 3). Fig. 6 shows the ratio of stiffness of the cross-sectional span against support cross-section stiffness, depending on the duration of the fire.

A relative decrease in stiffness span cross-sections (with heated reinforcement) occurs much faster than support cross-sections (with heated concrete compression zone). In all examined span cross-sections, regardless of their height in the initial phase of the fire $(t=30 \mathrm{~min})$ more than $60 \%$ reduction in stiffness has

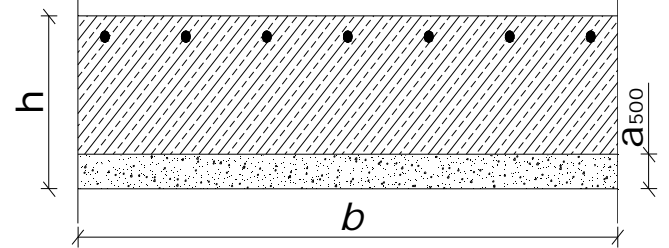

Fig. 4 Reduced cross-section of a slab considered in calculation. 
Table 3 Key results of the calculations.

\begin{tabular}{clllllll}
\hline (a) A span slab $7.2 \mathrm{~m}(h=25 \mathrm{~cm})$ \\
\hline$t$ (min) & $a_{500}(\mathrm{~cm})$ & $M_{R d}(\mathrm{kNm})$ & $M_{q p}(\mathrm{kNm})$ & $B_{I}\left(\mathrm{kNm}^{2}\right)$ & $B_{I I}\left(\mathrm{kNm}^{2}\right)$ & $B_{f i}\left(\mathrm{kNm}^{2}\right)$ & $B_{f i} / B_{f i}(t=0)$ \\
\hline 0 & 0.0 & 123.1 & 68.1 & 15,797 & 6,449 & 6,847 & 1.00 \\
30 & 0.9 & 117.8 & 68.1 & 14,540 & 5,865 & 6,177 & 0.90 \\
60 & 2.0 & 111.3 & 68.1 & 13,152 & 5,190 & 5,421 & 0.79 \\
90 & 2.7 & 107.1 & 68.1 & 12,352 & 4,784 & 4,974 & 0.73 \\
120 & 3.5 & 102.4 & 68.1 & 11,514 & 4,342 & 4,492 & 0.66 \\
180 & 4.7 & 95.3 & 68.1 & 10,402 & 3,722 & 3,827 & 0.56 \\
240 & 5.7 & 89.4 & 68.1 & 9,601 & 3,244 & 3,321 & 0.48
\end{tabular}

(b) A span slab $6.0 \mathrm{~m}(h=20 \mathrm{~cm})$

\begin{tabular}{clllllll}
\hline$t(\min )$ & $a_{500}(\mathrm{~cm})$ & $M_{R d}(\mathrm{kNm})$ & $M_{q p}(\mathrm{kNm})$ & $B_{I}\left(\mathrm{kNm}^{2}\right)$ & $B_{I I}\left(\mathrm{kNm}^{2}\right)$ & $B_{f i}\left(\mathrm{kNm}^{2}\right)$ & $B_{f i} / B_{f i}(t=0)$ \\
\hline 0 & 0.0 & 76.8 & 41.6 & 7,945 & 3,078 & 3,295 & 1.00 \\
30 & 0.9 & 72.5 & 41.6 & 7,142 & 2,718 & 2,878 & 0.87 \\
60 & 2.0 & 67.2 & 41.6 & 6,279 & 2,312 & 2,420 & 0.73 \\
90 & 2.7 & 63.9 & 41.6 & 5,794 & 2,071 & 2,155 & 0.65 \\
120 & 3.5 & 60.0 & 41.6 & 5,300 & 1,814 & 1,876 & 0.57 \\
180 & 4.7 & 54.3 & 41.6 & 4,669 & 1,463 & 1,501 & 0.46 \\
240 & 5.7 & 49.5 & 41.6 & 4,240 & 1,201 & 1,225 & 0.37 \\
\hline
\end{tabular}

(c) A span slab $4.8 \mathrm{~m}(h=16 \mathrm{~cm})$

\begin{tabular}{clllllll}
\hline$t(\min )$ & $a_{500}(\mathrm{~cm})$ & $M_{R d}(\mathrm{kNm})$ & $M_{q p}(\mathrm{kNm})$ & $B_{I}\left(\mathrm{kNm}^{2}\right)$ & $B_{I I}\left(\mathrm{kNm}^{2}\right)$ & $B_{f i}\left(\mathrm{kNm}^{2}\right)$ & $B_{f i} / B_{f i}(t=0)$ \\
\hline 0 & 0.0 & 46.2 & 23.8 & 3,974 & 1,406 & 1,540 & 1.00 \\
30 & 0.9 & 42.8 & 23.8 & 3,458 & 1,193 & 1,283 & 0.83 \\
60 & 2.0 & 38.6 & 23.8 & 2,923 & 958 & 1,012 & 0.66 \\
90 & 2.7 & 36.0 & 23.8 & 2,633 & 824 & 862 & 0.56 \\
120 & 3.5 & 33.0 & 23.8 & 2,347 & 683 & 708 & 0.46 \\
180 & 4.7 & 28.5 & 23.8 & 2,002 & 498 & 511 & 0.33 \\
228 & 5.5 & 25.4 & 23.8 & 1,823 & 393 & 401 & 0.26 \\
\hline
\end{tabular}

(d) A span slab $3.6 \mathrm{~m}(h=12 \mathrm{~cm})$

\begin{tabular}{clllllll}
\hline$t(\min )$ & $a_{500}(\mathrm{~cm})$ & $M_{R d}(\mathrm{kNm})$ & $M_{q p}(\mathrm{kNm})$ & $B_{I}\left(\mathrm{kNm}^{2}\right)$ & $B_{I I}\left(\mathrm{kNm}^{2}\right)$ & $B_{f i}\left(\mathrm{kNm}^{2}\right)$ & $B_{f i} / B_{f i}(t=0)$ \\
\hline 0 & 0.0 & 23.6 & 11.8 & 1,623 & 490 & 558 & 1.00 \\
30 & 0.9 & 21.1 & 11.8 & 1,333 & 384 & 423 & 0.76 \\
60 & 2.0 & 18.0 & 11.8 & 1,047 & 274 & 292 & 0.52 \\
90 & 2.7 & 16.0 & 11.8 & 902 & 214 & 225 & 0.40 \\
120 & 3.5 & 13.8 & 11.8 & 768 & 156 & 162 & 0.29 \\
156 & 4.0 & 12.4 & 11.8 & 700 & 124 & 128 & 0.23 \\
\hline
\end{tabular}

been reached. The support cross-sections of the stiffness is reduced, the faster, the lower section height. The ratio of stiffness of the span cross-section against support cross-section stiffness has fallen twice after 30 min of fire for all the thicknesses. A significant change in the proportion of the stiffness of the span and support cross-sections should lead to a substantial redistribution of bending moments, which is an increase support for reducing the span of the moments.

\section{Stiffness of Cross-Section RC Beams under Fire Conditions}

\subsection{Assumptions}

Considered two beams (two-span), one span is 6.0 $\mathrm{m}$ and another is $7.5 \mathrm{~m}$. It was assumed that the beam with a $\operatorname{span} l=6.0 \mathrm{~m}$ takes the load from the slab with a width of $4.20 \mathrm{~m}(h=25 \mathrm{~cm})$, and the beam with a span $l=7.5 \mathrm{~m}$ slabs width $7.5 \mathrm{~m}(h=25 \mathrm{~cm})$. Slabs variable 


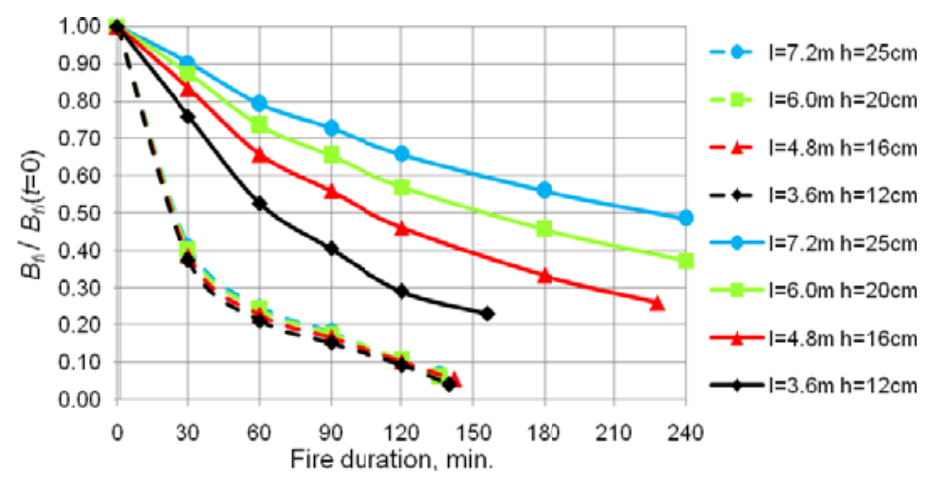

Fig. 5 Stiffness ratio of slabs cross-section, calculated for successive durations of fire, against the initial stiffness, continuous lines-support cross-sections, dashed lines—span cross-sections.

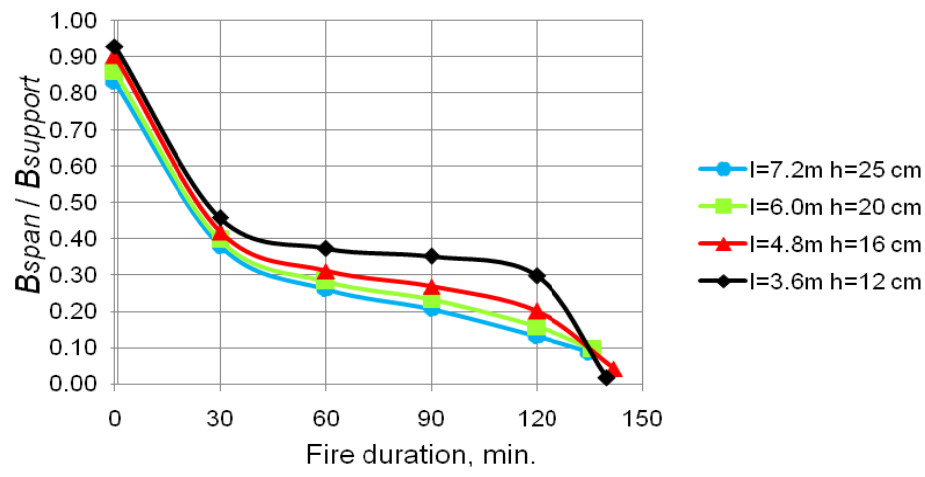

Fig. 6 The ratio of stiffness of span cross-section against the support cross-section stiffness, depending on the duration of fire.

Table 4 Key parameters of considered beams.

\begin{tabular}{|c|c|c|c|c|c|c|c|c|c|}
\hline \multirow{2}{*}{$\begin{array}{l}\text { Length } \\
l(\mathrm{~m})\end{array}$} & \multirow{2}{*}{$\begin{array}{l}\text { Cross-section } \\
b \times h(\mathrm{~m})\end{array}$} & \multicolumn{2}{|c|}{ Moment $(\mathrm{kNm})$} & \multicolumn{3}{|c|}{ Span reinforcement } & \multicolumn{3}{|c|}{ Support reinforcement } \\
\hline & & Span & Support & $\eta$ & $A_{s}$ & $\rho(\%)$ & $\eta$ & $A_{s}$ & $\rho(\%)$ \\
\hline 6.00 & $0.25 \times 0.50$ & 130.8 & 178.1 & 0.62 & $4 \varnothing 20$ & 1.10 & 0.66 & $6 ø 20$ & 1.68 \\
\hline 7.50 & $0.35 \times 0.70$ & 369.5 & 583.4 & 0.62 & $7 \varnothing 20$ & 0.97 & 0.66 & $12 \varnothing 20$ & 1.66 \\
\hline
\end{tabular}

loads and combinations of load assumed in the same way as described in Section 2.1. Adopted C30/37 concrete, main reinforcement steel with characteristic yield strength $f_{y k}=500 \mathrm{MPa}$, distance from the axis of the main bars from the edge of the cross-section is 50 $\mathrm{mm}$.

Cross-sections of beams and reinforcement bars were chosen such that they satisfy the conditions of the boundary condition and load bearing capacity and serviceability to the degree of reinforcement span cross-section is close to $1 \%$. In Table 4 , they are the most important information about the beams.

Stiffness of the beam cross-sections were determined based on assumptions of the 500 ${ }^{\circ} \mathrm{C}$-isotherm method, as described in Section 2. The following presents important information on procedures for the performed calculations.

\subsection{The Procedure for Calculating Cross-Sectional Stiffness (Heated Reinforcement)}

First, similarly as in Section 2.2, the calculations were performed for the duration of the fire, $t=0 \mathrm{~min}$. Beams $l=6.0 \mathrm{~m}$ and $l=7.5 \mathrm{~m}$ were adopted accordingly: $\varphi=2.37, E_{c, \text { eff }}=9.74 \mathrm{GPa}, \varphi=2.26, E_{c, \text { eff }}$ $=10.07 \mathrm{GPa}$. In order to calculate the stiffness of the cross-section on fire conditionsit, it is necessary to estimate the temperature of reinforcement $\left(\theta_{s}\right)$ and the corresponding resultant modulus of steel $\left(E_{s, f i}\right)$. Resultant modulus of elasticity of steel is calculated analogously to the slab on the basis of Fig. 2 and Eq. (5). 
Reinforcement temperature $\left(\theta_{s}\right)$ is estimated on the basis of Fig. 7 [10]. They are the guidelines for a simplified prediction of the temperature of the reinforcement in reinforced concrete beams cross-sections exposed to standard fire.

In considering the beams, it should be taken into account that the temperature of the bars located in the corners of the cross-section is higher than that of bars located in the central part. This is reflected in the guidance given in Fig. 7. In the calculations the corner and the middle bars temperatures have been set, then the resultant temperature was estimated as a weighted average, depending on the number of corner bars and the middle bars. Table 5 shows the estimated bars temperature value.

On the basis of the average temperature it was specified value of resultant (secant) modulus elasticity of steel, based on the graphs shown in Fig. 2.

Stiffness of the cross-section was calculated by Eq. (4). Calculations have been done to the time at which

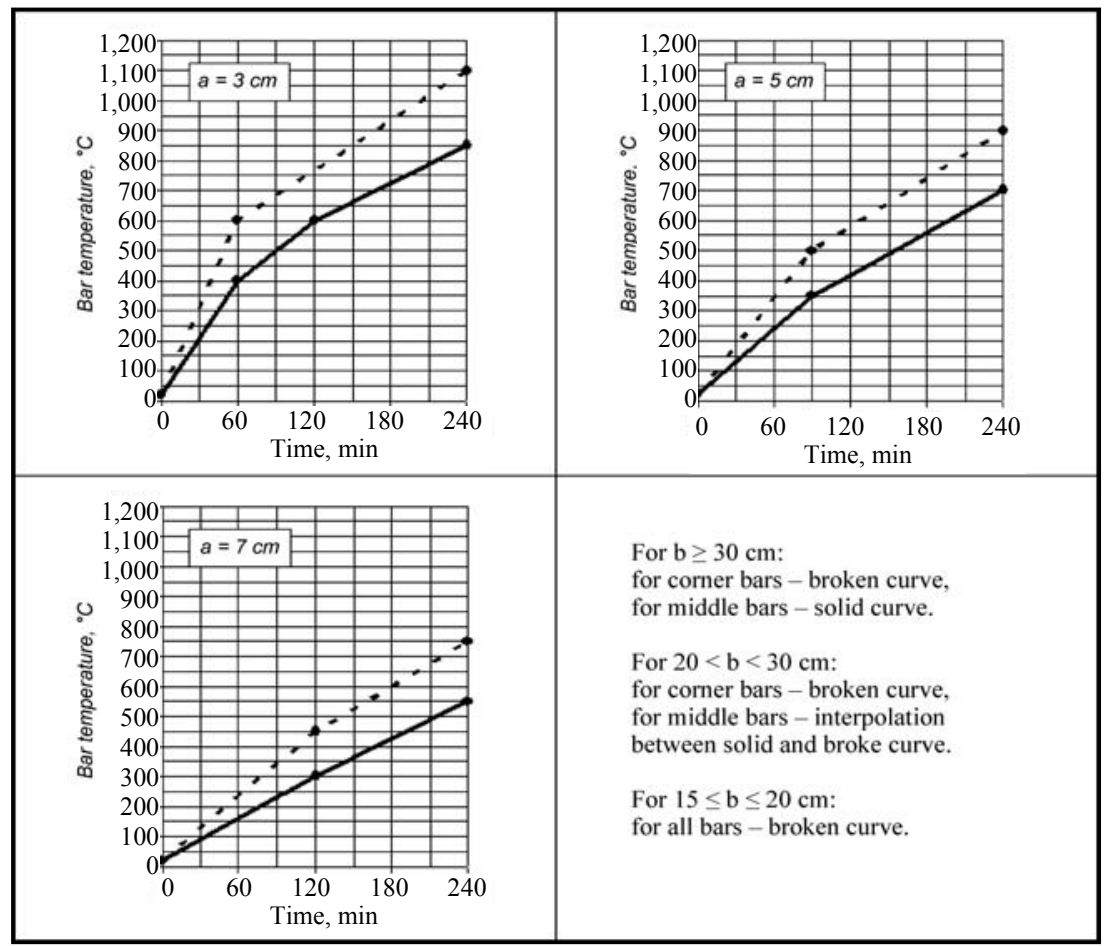

Fig. 7 Temperature of the reinforcing bars in RC beams subjected to standard fire [10] ( $a$ - distance between the bar axis and the surface of the concrete; $\boldsymbol{b}$-cross-section width).

Table 5 Estimated temperature of bars.

\begin{tabular}{|c|c|c|c|c|c|c|}
\hline \multirow{3}{*}{$\begin{array}{l}\text { Fire } \\
t \\
\text { Min }\end{array}$} & \multicolumn{6}{|c|}{ Estimated temperature of bars $\left({ }^{\circ} \mathrm{C}\right)$} \\
\hline & \multicolumn{3}{|c|}{$L=6.0 \mathrm{~m}(2 \varnothing \mathrm{cor}+2 \varnothing \mathrm{midd})$} & \multicolumn{3}{|c|}{$L=7.5 \mathrm{~m}(2 \varnothing \mathrm{cor}+5 \varnothing \mathrm{midd})$} \\
\hline & Corner & Middle & Average & Corner & Middle & Average \\
\hline 0 & 20 & 20 & 20 & 20 & 20 & 20 \\
\hline 30 & 180 & 155 & 168 & 180 & 130 & 144 \\
\hline 60 & 340 & 290 & 315 & 340 & 240 & 269 \\
\hline 90 & 500 & 425 & 463 & 500 & 350 & 393 \\
\hline 120 & 570 & 495 & 533 & 570 & 420 & 463 \\
\hline 180 & 710 & 635 & 673 & 710 & 560 & 603 \\
\hline 240 & 850 & 775 & 813 & 850 & 700 & 743 \\
\hline
\end{tabular}


Table 6 Key results of the calculations.

\begin{tabular}{cccccccccc}
\hline \multicolumn{2}{l}{ (a) A span of beam $6.0 \mathrm{~m}(25 \times 50 \mathrm{~cm})}$. \\
\hline$t(\mathrm{~min})$ & $\theta_{s}\left({ }^{\circ} \mathrm{C}\right)$ & $\sigma_{s}(\mathrm{MPa})$ & $f_{s y, \Theta}(\mathrm{MPa})$ & $\varepsilon_{s, t o t}(\%)$ & $E_{s, f i}(\mathrm{GPa})$ & $B_{I}\left(\mathrm{kNm}^{2}\right)$ & $B_{I I}\left(\mathrm{kNm}^{2}\right)$ & $B_{f i}\left(\mathrm{kNm}^{2}\right)$ & $B_{f i} / B_{f i}(t=0)$ \\
\hline 0 & 20 & 249 & 500 & 1.24 & 200.0 & 58,662 & 37,409 & 38,513 & 1.00 \\
30 & 168 & 242 & 500 & 3.22 & 77.3 & 62,297 & 16,215 & 16,754 & 0.44 \\
60 & 315 & 240 & 500 & 5.48 & 44.2 & 52,189 & 9,721 & 9,979 & 0.26 \\
90 & 463 & 238 & 430 & 8.37 & 28.7 & 42,808 & 6,477 & 6,607 & 0.17 \\
120 & 533 & 237 & 340 & 20.82 & 20.8 & 37,001 & 4,791 & 4,870 & 0.13 \\
148 & 597 & 235 & 238 & 26.40 & 9.0 & 28,876 & 2,138 & 2,163 & 0.06 \\
\hline (b) A span & of beam $7.5 \mathrm{~m}(35 \times 70 \mathrm{~cm})$ & & & & & & \\
\hline$t$ (min) & $\theta_{s}\left({ }^{\circ} \mathrm{C}\right)$ & $\sigma_{s}(\mathrm{MPa})$ & $f_{s y, \Theta}(\mathrm{MPa})$ & $\varepsilon_{s, t o t}(\%)$ & $E_{s, f i}(\mathrm{GPa})$ & $B_{I}(\mathrm{kNm})$ & $B_{I I}\left(\mathrm{kNm}^{2}\right)$ & $B_{f i}\left(\mathrm{kNm}^{2}\right)$ & $B_{f i} / B_{f i}(t=0)$ \\
\hline 0 & 20 & 276 & 500 & 1.38 & 200.0 & 202,491 & 140,242 & 142,500 & 1.00 \\
30 & 144 & 271 & 500 & 3.01 & 91.7 & 240,802 & 703,511 & 72,294 & 0.51 \\
60 & 269 & 268 & 500 & 4.90 & 55.3 & 206,929 & 44,210 & 45,237 & 0.32 \\
90 & 393 & 266 & 500 & 7.24 & 37.0 & 181,891 & 30,437 & 31,031 & 0.22 \\
120 & 463 & 266 & 430 & 29.43 & 29.4 & 166,877 & 24,513 & 24,938 & 0.18 \\
148 & 578 & 263 & 267 & 25.29 & 10.5 & 136,263 & 9,138 & 9,259 & 0.06
\end{tabular}

ULS has occurred. Table 6 presents the main results of the calculations.

\subsection{The Procedure for Calculating the Stiffness of the} Support Cross-Section (Heated Compressed Zone of Concrete)

First calculations for the beginning of the fire have been performed. Then, based on Eq. (4) calculated cross-sectional stiffness $\left(B_{f i}\right)$ for successive durations of fire. According to the assumptions of the $500{ }^{\circ} \mathrm{C}$-isotherm method [9] dealt with a reduced cross-sectional size (Fig. 8), and unchanged mechanical characteristics of reinforcement $\left(E_{s}=200\right.$ $\left.\mathrm{GPa}, f_{y k}=500 \mathrm{MPa}\right)$ and concrete $\left(E_{c, \text { eff }}=10.63 \mathrm{GPa}\right.$ and $9.94 \mathrm{GPa}$ for $h=25 \mathrm{~cm}$ and $12 \mathrm{~cm}$, respectively.
Location of $500{ }^{\circ} \mathrm{C}$ isotherms in the cross-section was estimated on the basis of Fig. 9 [10]. They are the guidelines for a simplified forecasting $500{ }^{\circ} \mathrm{C}$ isotherm distance from the side edge $\left(a_{X}\right)$ and lower edge $\left(a_{Y}\right)$ of the cross-section reinforced concrete beams exposed to standard fire. Table 7 shows the main results of the calculations.

\subsection{Analysis of Stiffness Reduction in Cross-Section of Beams}

Fig. 10 shows the ratio of the stiffness of the cross-section, calculated for successive durations of the fire against the initial stiffness $\left(B_{f i} / B_{f i}(t=0)\right)$, for span and support cross-sections (Tables 6 and 7). Fig. 11 shows the ratio of stiffness of span cross-section against

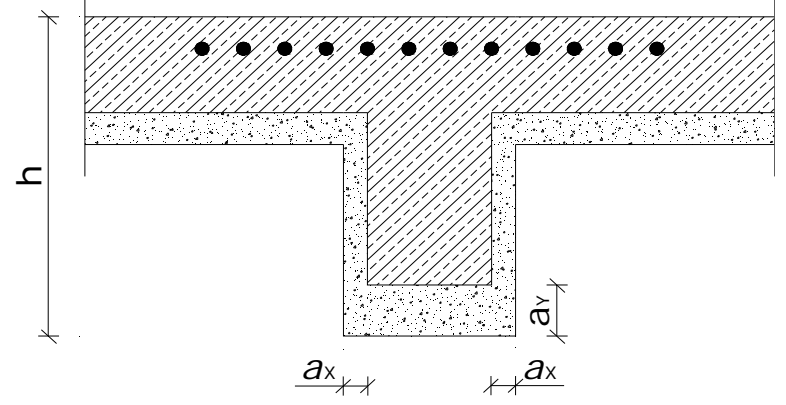

Fig. 8 Reduced cross-section of a beam considered in calculation. 


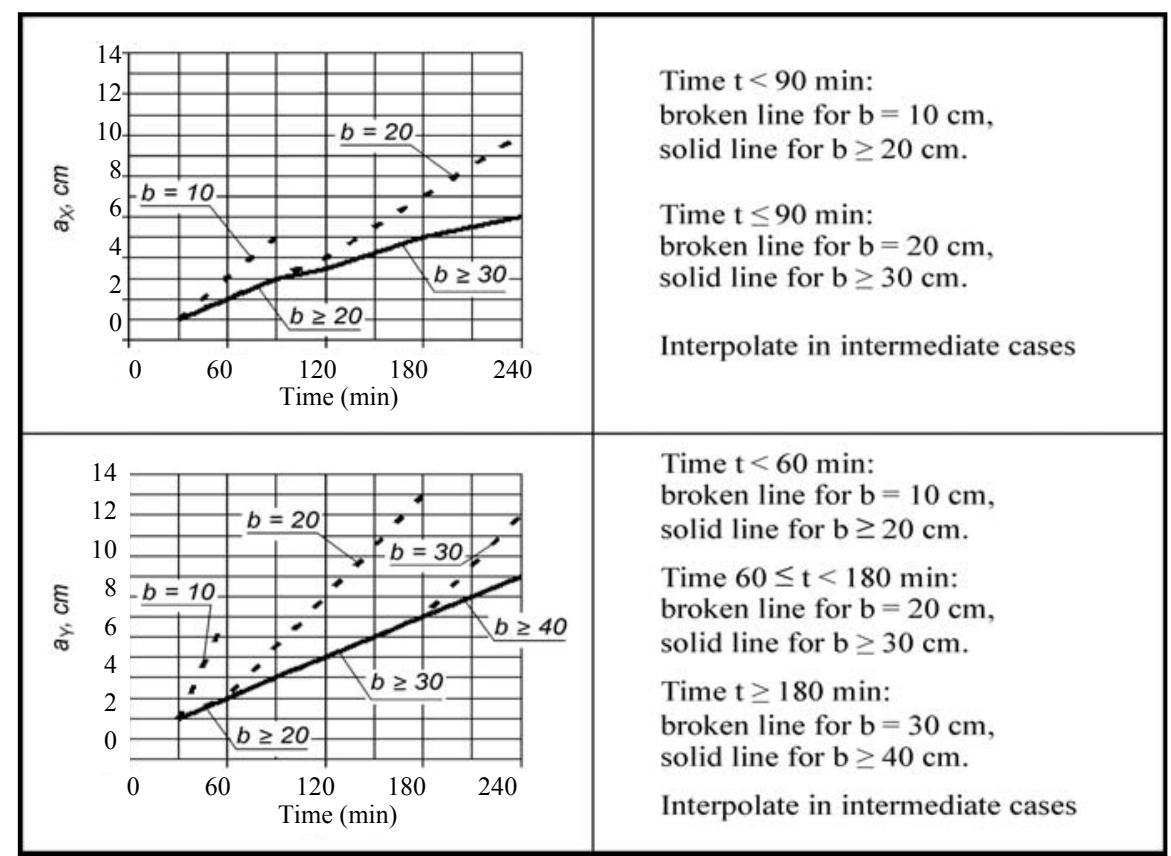

Fig. 9 Position of the $500{ }^{\circ} \mathrm{C}$-isotherm in RC beams subjected to standard fire [10] $\left(a_{X}\right.$-measured from the lateral side and $a_{Y}$ - measured from the bottom side).

Table 7 Key results of the calculations.

\begin{tabular}{cllllllll}
\hline \multicolumn{2}{l}{ (a) A span of beam $6.0 \mathrm{~m}(25 \times 50 \mathrm{~cm})$} \\
\hline$t(\mathrm{~min})$ & $a_{X}(\mathrm{~cm})$ & $a_{Y}(\mathrm{~cm})$ & $M_{R d}(\mathrm{kNm})$ & $M_{q p}(\mathrm{kNm})$ & $B_{I}\left(\mathrm{kNm}^{2}\right)$ & $B_{I I}\left(\mathrm{kNm}^{2}\right)$ & $B_{f i}\left(\mathrm{kNm}^{2}\right)$ & $B_{f i} / B_{f i}(t=0)$ \\
\hline 0 & 0.0 & 0.0 & 366.1 & 206.2 & 37,296 & 28,463 & 28,790 & 1.00 \\
30 & 1.0 & 2.0 & 339.6 & 206.2 & 66,708 & 24,456 & 24,880 & 0.86 \\
60 & 2.0 & 3.0 & 321.6 & 206.2 & 56,062 & 22,050 & 22,318 & 0.78 \\
90 & 3.0 & 4.8 & 294.1 & 206.2 & 43,962 & 18,754 & 18,896 & 0.66 \\
120 & 3.5 & 6.5 & 271.7 & 206.2 & 36,469 & 16,323 & 16,412 & 0.57 \\
165 & 5.8 & 9.3 & 206.9 & 206.2 & 20,531 & 11,315 & 11,333 & 0.39 \\
\hline
\end{tabular}

(b) A span of beam $7.5 \mathrm{~m}(35 \times 70 \mathrm{~cm})$

\begin{tabular}{cllllllll}
\hline$t(\min )$ & $a_{X}(\mathrm{~cm})$ & $a_{Y}(\mathrm{~cm})$ & $M_{R d}(\mathrm{kNm})$ & $M_{q p}(\mathrm{kNm})$ & $B_{I}\left(\mathrm{kNm}^{2}\right)$ & $B_{I I}\left(\mathrm{kNm}^{2}\right)$ & $B_{f i}\left(\mathrm{kNm}^{2}\right)$ & $B_{f i} / B_{f i}(t=0)$ \\
\hline 0 & 0.0 & 0.0 & $1,041.2$ & 583.4 & 153,669 & 119,706 & 121,026 & 1.00 \\
30 & 1.0 & 2.0 & 989.7 & 583.4 & 283,328 & 107,916 & 109,831 & 0.91 \\
60 & 2.0 & 3.0 & 955.9 & 583.4 & 251,194 & 100,718 & 102,112 & 0.84 \\
90 & 3.0 & 4.8 & 904.6 & 583.4 & 212,888 & 90,611 & 91,520 & 0.76 \\
120 & 3.5 & 6.5 & 862.7 & 583.4 & 187,701 & 82,876 & 83,537 & 0.69 \\
180 & 6.0 & 10.0 & 737.4 & 583.4 & 123,388 & 63,875 & 64,087 & 0.53 \\
240 & 8.0 & 12.0 & 630.7 & 583.4 & 87,325 & 52,027 & 52,104 & 0.43 \\
\hline
\end{tabular}

the stiffness of the support cross-section depending on the duration of the fire.

As in the case of examined slabs, the relative reduction of span cross-sections stiffness (with heated reinforcement) occurs much faster than cross-sections of the support (with heated concrete compression zone).
In span cross-sections, already in the initial phase of the fire $(t=30 \mathrm{~min})$ more than $50 \%$ reduction in stiffness has been reached. Stiffness in the cross-sections of the support is reduced more quickly, the cross-sectional dimensions are smaller. The ratio of span stiffness to the support decreased approximately 


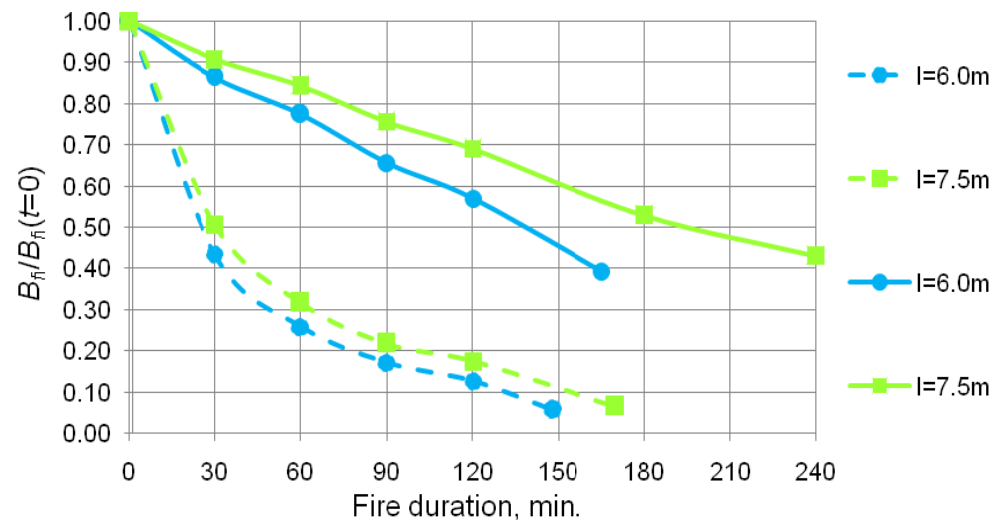

Fig. 10 Stiffness ratio of the beam cross-section, calculated for successive durations of fire to the initial stiffness, solid lines-support cross-sections, broken lines—span cross-sections.

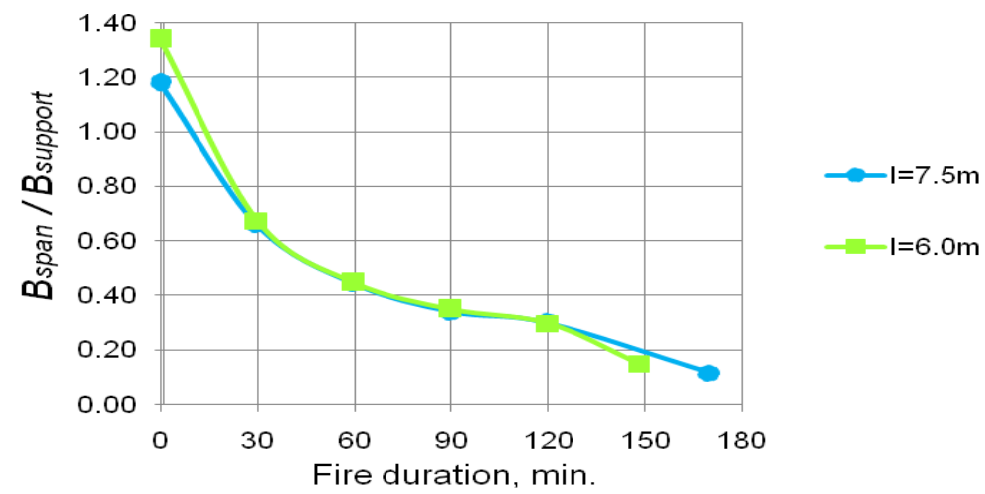

Fig. 11 The ratio of stiffness of span cross-section beams against the stiffness of the support cross-section, depending on the duration of the fire.

twice after $30 \mathrm{~min}$ of the fire duration.

\section{Redistribution of Bending Moments}

\subsection{The Assumptions and Calculation Procedure}

Effect of changes in the stiffness of cross-sections in fire conditions on the redistribution of bending moments is defined in the examples: (1) two-span beams with span length of $7.5 \mathrm{~m}$, cross-section $b \times h=$ $30 \times 70 \mathrm{~cm}$; (2) two-span slabs with span length $7.2 \mathrm{~m}$, cross-section height $h=25 \mathrm{~cm}$.

Using a computer program (Finite Element Method Robot 2010) has been made calculations of bending moments in the designed permanent situation and accidental situation for the successive durations of fire in slabs and beams. In the locations of the (positive) sagging bending moments for the calculation of the heated sections of the reinforcement (span), has been taken the stiffness defined in Section 2.2 or 3.2. In the locations of the (negative) hogging bending moments assumed rigidity of the heated sections of concrete compression zone (the support), as defined in Section 2.3 or 3.3 .

The paper presents the calculation results obtained in two the less favourable cases of the variable load location and operation of the fire (Fig. 12):

(1) Variable load is located on one span only, which is subjected to the action of fire from the bottom (Fig. 12a);

(2) Variable load is placed on both spans, which are subjected to the action of fire from the bottom (Fig. 12b).

4.2 Beam with a $7.5 \mathrm{~m}$ Span Length, Cross-Section $b \times$ $h=30 \times 70 \mathrm{~cm}$

Fig. 13 shows diagrams of bending moments in the 
(a)

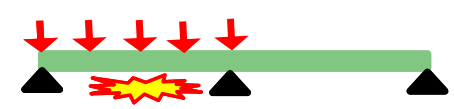

(b)

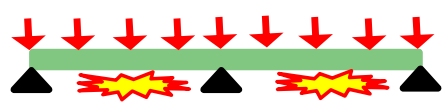

Fig. 12 Cases of variable loads and location of the impact of fire 4.2 beam with a $7.5 \mathrm{~m}$ span length, cross-section $b \times h=30 \times$ $70 \mathrm{~cm}$.
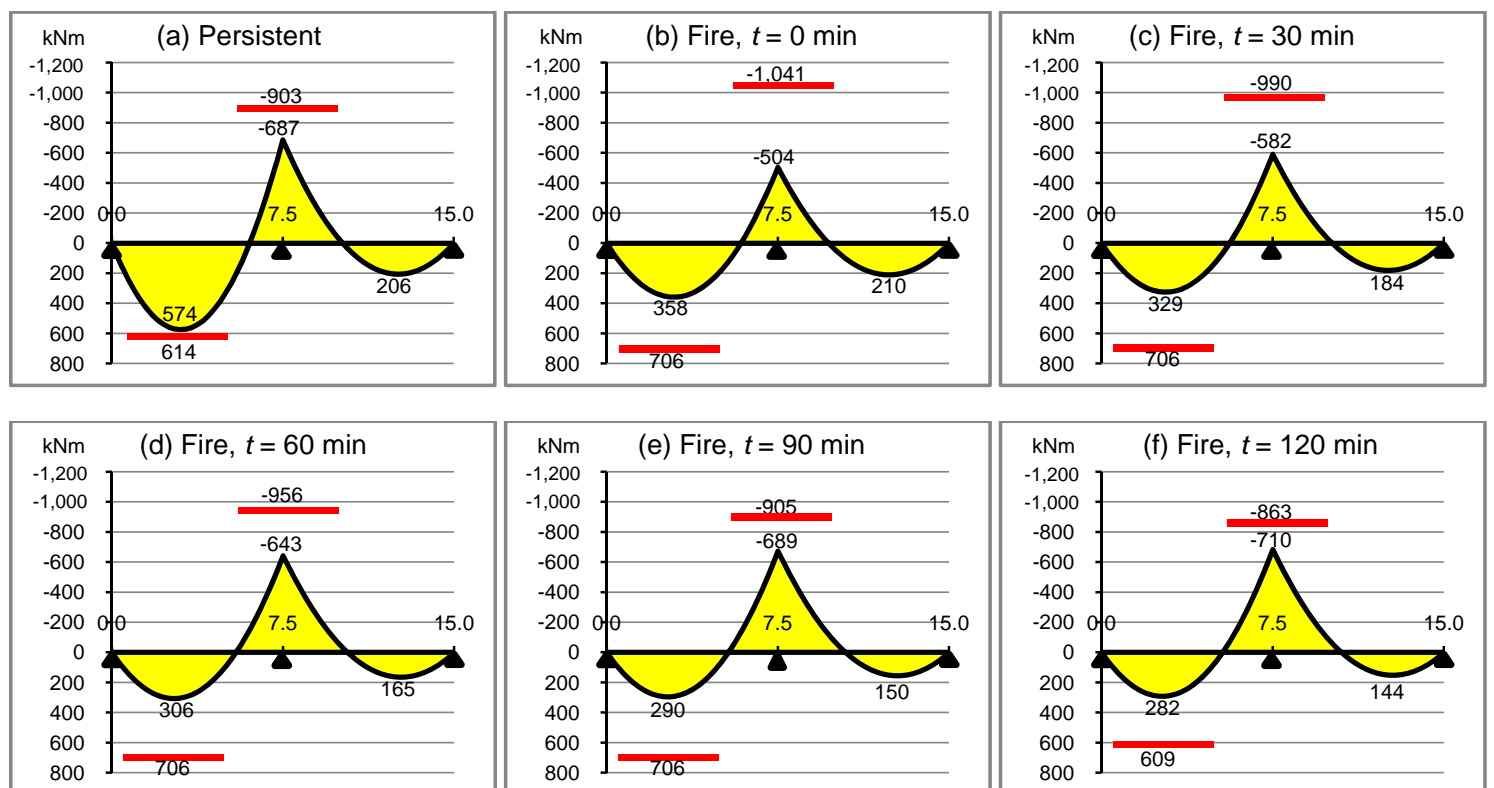

Fig. 13 Bending moments in $7.5 \mathrm{~m}$ span length beam, cross-section $35 \times 70 \mathrm{~cm}$, variable load and fire in one span only (a-f).

beam exposed to variable load and fire in one span only (according to Fig. 12a) in a persistent design situation, and in subsequent fire durations. The short horizontal lines correspond to the values of calculated load bearing capacity.

Fig. 14 shows the comparison between the calculated bending moment and calculated load bearing capacity, in span and support cross-sections of the beam shown in Fig. 13.

Figs. 15 and 16, in the same manner, present graphs of bending moments in the same beam, where a variable load and fire operate on both spans (Fig. 12b).

With the "transition" from persistent design situation to accidental situation of a fire (Figs. 13a and 13b, Figs. 15a and 15b) the calculated load bearing capacity greatly increases. Then, as the fire effect, span moments decrease and support moments increase.

In span cross-sections (Figs. 14 and 16) slightly decreasing calculated moment "moves away" from the rapidly decreasing calculated load bearing capacity. This causes a slight delay of a computational load limit state in cross-sections of the span.

In the cross-sections of the support (Figs. 14 and 16) rapidly growing calculated moment soon, "approaches" the decreasing calculated load bearing capacity. This results in a significant acceleration of ultimate limit state in cross-sections of the support.

Consequently, as a result of redistribution of bending moments, the calculated ultimate limit state occurs firstly in the support cross-section, and then in cross-section of the span. If omitted the redistribution of bending moments would be the reverse situation. ULS occurs in the first in the span cross-section, and then in the support cross-section.

Please note that the occurrence of ULS in a support cross-section will result in re "descending" graph of bending moments, which was not considered in this paper. 

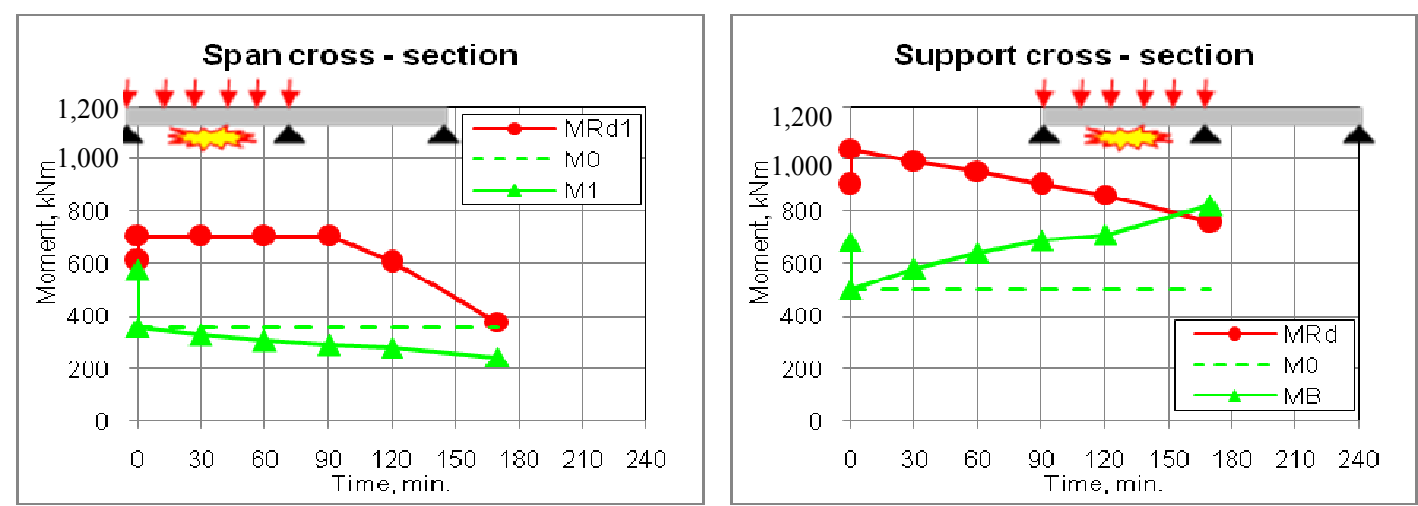

Fig. 14 Comparison of calculated bending moments and calculated load bearing capacity in span and support cross-sections: $7.5 \mathrm{~m}$ span length beam, cross-section $35 \times 70 \mathrm{~cm}$, variable load and fire in one span only, the top curve-calculated load bearing capacity, the second solid line—calculated bending moment, redistribution considered, the broken line—calculated bending moment, redistribution neglected.
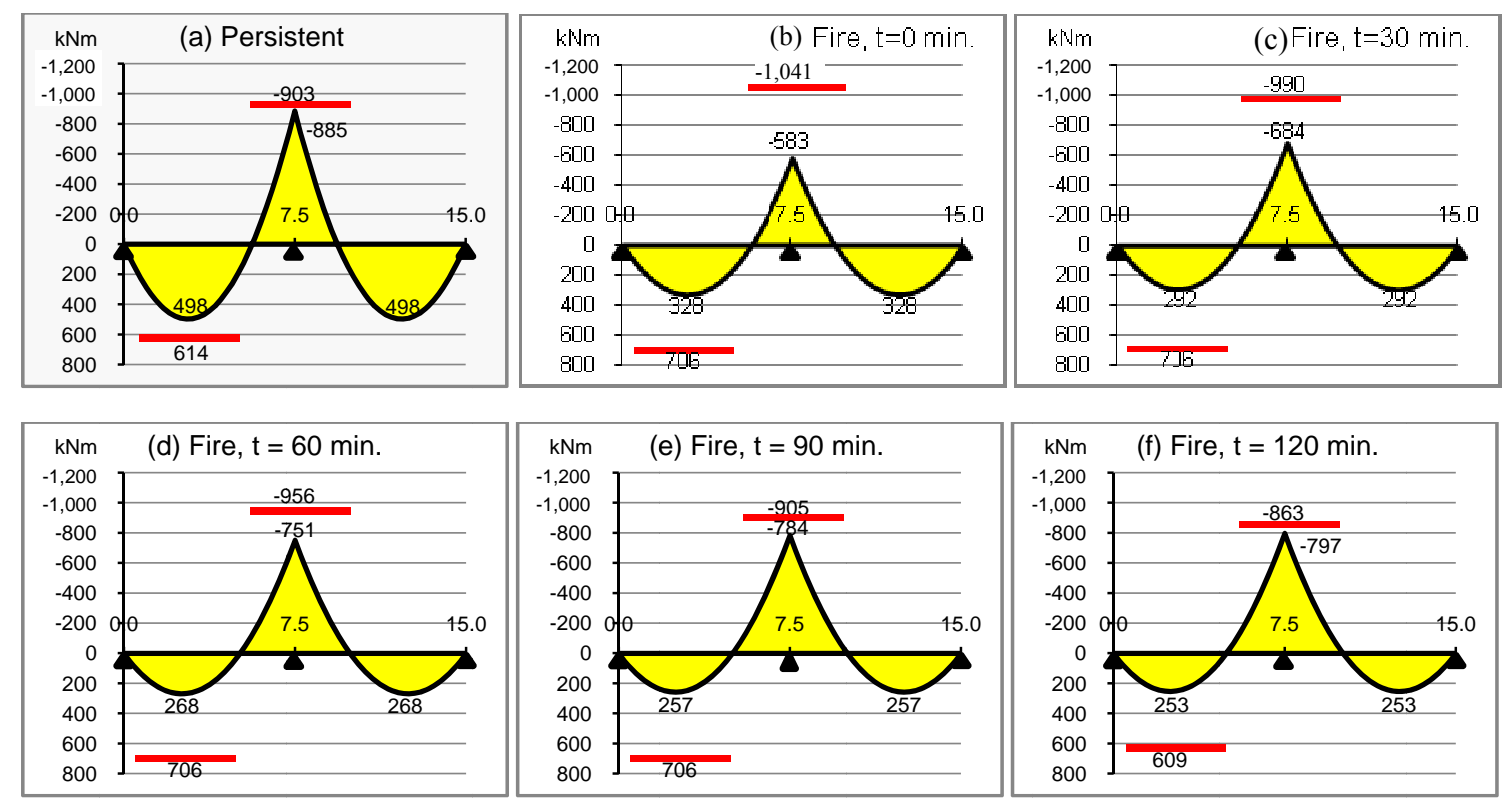

Fig. 15 Bending moments in $7.5 \mathrm{~m}$ span length beam, cross-section $35 \times 70 \mathrm{~cm}$, variable load and fire in both spans (a-f).
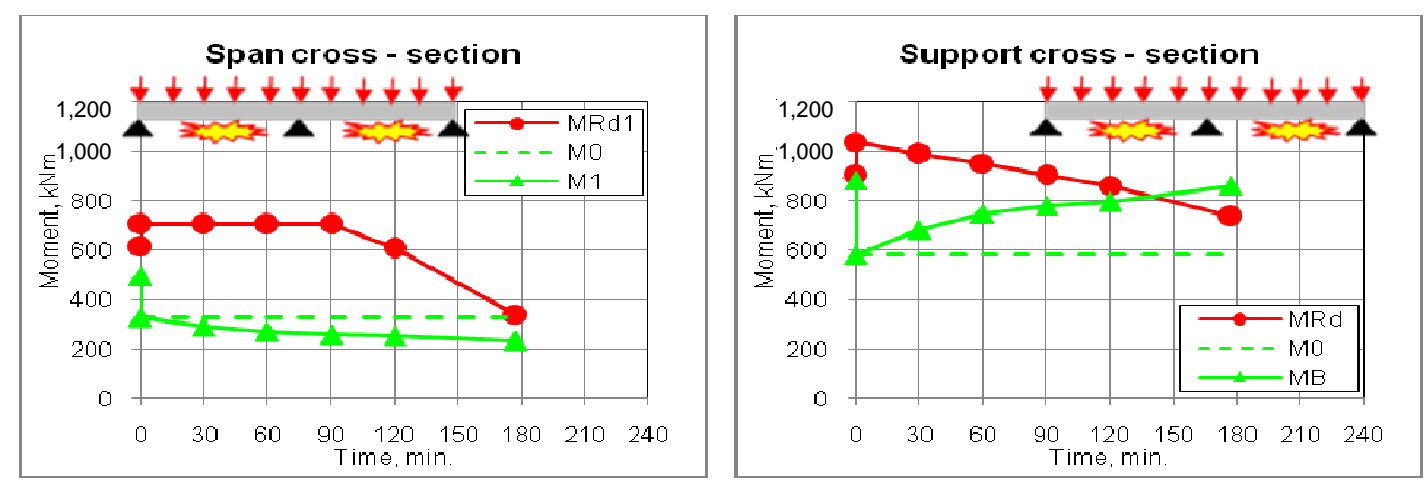

Fig. 16 Comparison of calculated bending moments and calculated load bearing capacity in span and support cross-sections: $7.5 \mathrm{~m}$ span length beam, cross-section $35 \times 70 \mathrm{~cm}$, variable load and fire in both spans, the top curve-calculated load bearing capacity, the second solid line—calculated bending moment, redistribution considered, the broken line—calculated bending moment, redistribution neglected. 
In conclusion it can be estimated that in the case of load and fire on the two spans (Fig. 16), as a result of redistribution of bending moments, calculated destruction of the beam occurs about 40 min earlier than it would appear according to the calculations with neglected redistribution of bending moments. In the case of load and fire in one span only, inclusion or omission of redistribution of bending moments is not essential for a fixed computational time of the beam destruction.

\subsection{Slab with a Span 7.2 $\mathrm{m}$, Height Cross-Section $h=$ $25 \mathrm{~cm}$}

Figs. 17-20 present graphs of bending moments in two span slabs of $7.2 \mathrm{~m}$ span length, cross-section height $h=25 \mathrm{~cm}$ in the same manner as in the previous chapter.

In the examined slab, a similar effect of redistribution of bending moments has been observed, as in the beam considered in Section 4.2. As a result of redistribution of bending moments, the ultimate limit state occurs firstly in cross-section of a support, and then in cross-section of span. In the case of the slab redistribution of bending moments, however, does not cause acceleration of ULS.

Figs. 18 and 20 show two aforementioned fire situations to cross-sections of the span and the support of the two span slab of $7.2 \mathrm{~m}$ span. The top
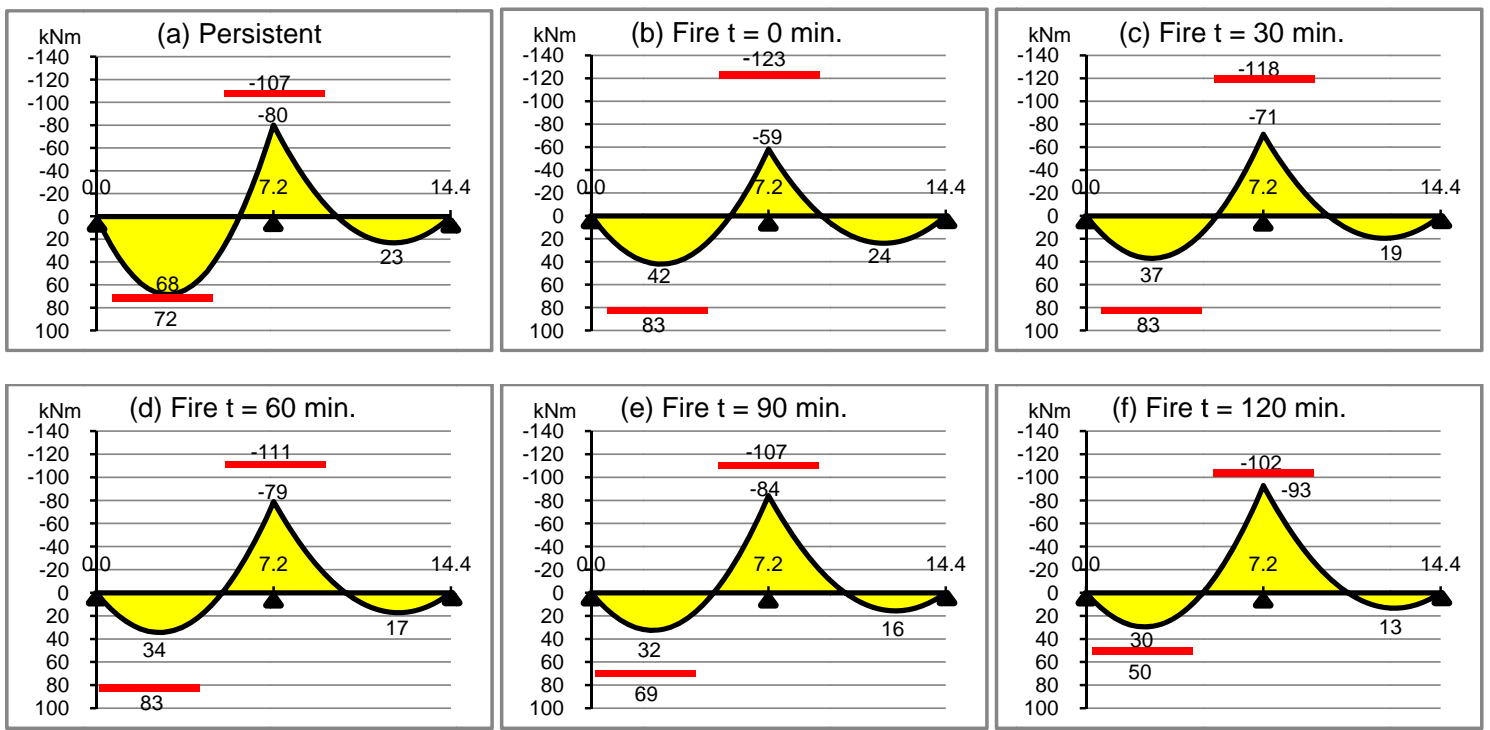

Fig. 17 Bending moments in $7.2 \mathrm{~m}$ span length slab, depth $25 \mathrm{~cm}$, variable load and fire in one span only (a-f).
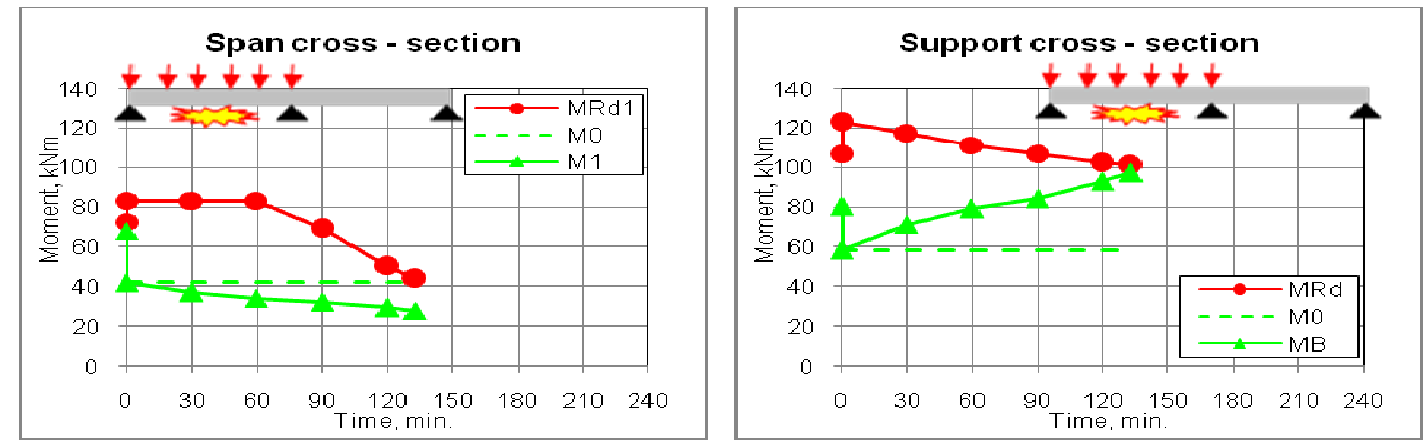

Fig. 18 Comparison of calculated bending moments and calculated load bearing capacity in span and support cross-sections: $7.2 \mathrm{~m}$ span length slab, cross-section depth $25 \mathrm{~cm}$, variable load and fire in one span only, the top curve-calculated load bearing capacity, the second solid line—calculated bending moment, redistribution considered, the broken line—calculated bending moment, redistribution. 

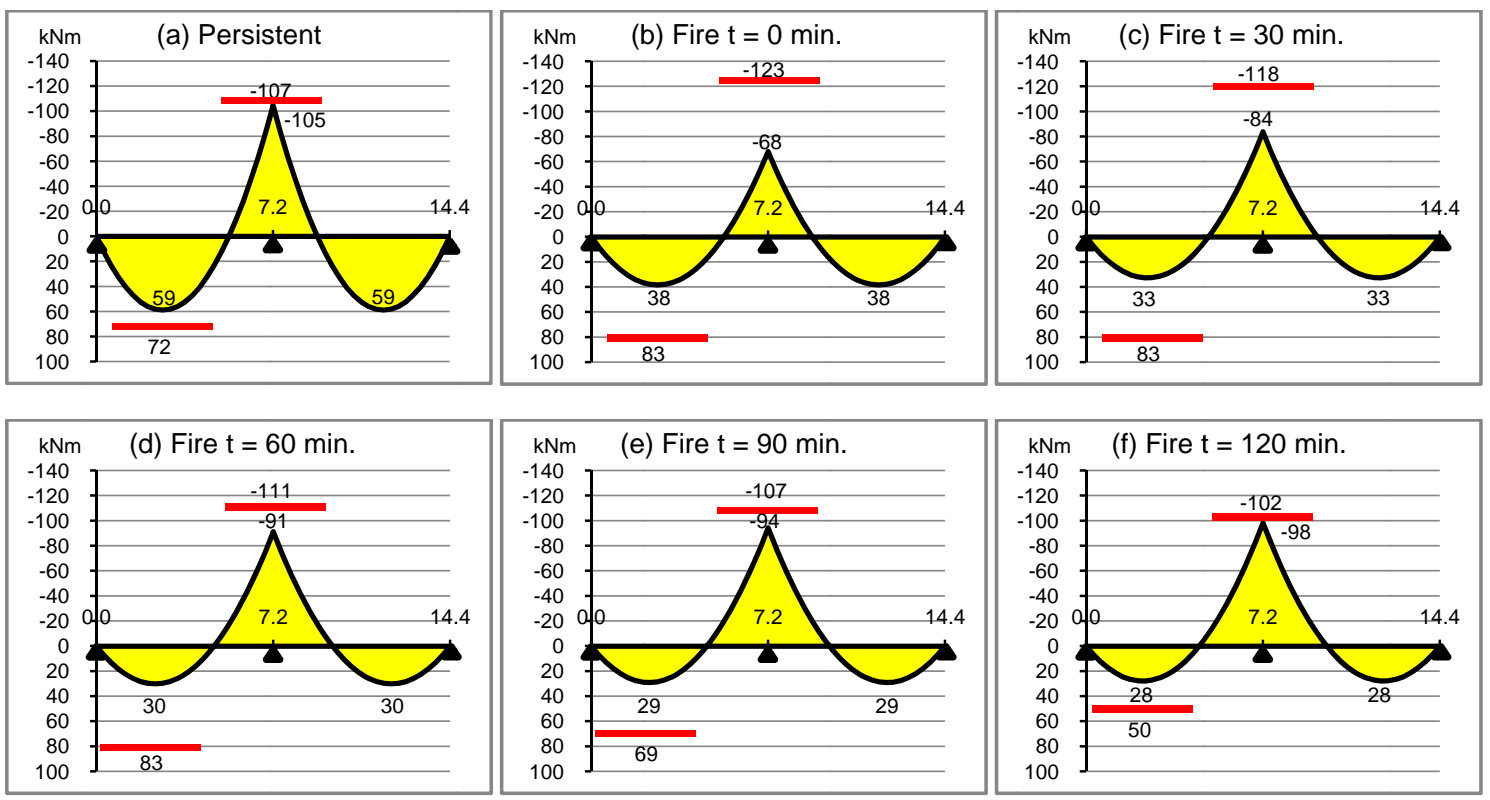

Fig. 19 Bending moments in $7.2 \mathrm{~m}$ span length slab, cross-section depth $25 \mathrm{~cm}$, variable load and fire in both spans (a-f).
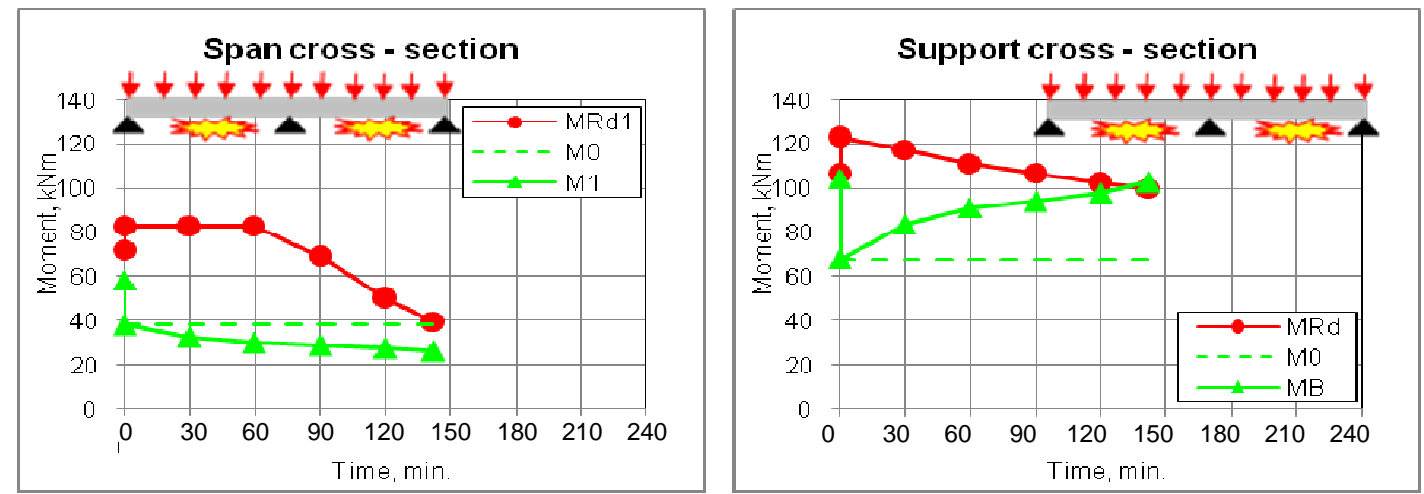

Fig. 20 Comparison of calculated bending moments and calculated load bearing capacity in span and support cross-sections: $7.2 \mathrm{~m}$ span length slab, cross-section depth $25 \mathrm{~cm}$, variable load and fire in both spans, the top curve-calculated load bearing capacity, the second solid line—calculated bending moment, redistribution considered, the broken line—calculated bending moment, redistribution.

curve - calculated load bearing capacity, the second solid line - calculated bending moment, redistribution considered, the broken line-calculated bending moment, redistribution.

\section{Conclusions}

In the first part of the paper it has been analyzed computationally, how changes the stiffness of the encountered in practice cross-sections of slabs and cross-sections of reinforced concrete beams exposed to fire only on the tensile reinforcement, or only from the compression zone of concrete. The calculations were based on assumptions of the $500{ }^{\circ} \mathrm{C}$-isotherms method, recommended in Ref. [9] to calculate the load bearing capacity of reinforced concrete elements exposed to standard fire.

Reduction of span cross-sections stiffness (with heated reinforcement) occurs much faster than the reduction of support cross-sections stiffness (with heated concrete compression zone). Already in the initial phase of the fire $(t=30 \mathrm{~min})$ a ratio of span cross-section stiffness to the stiffness of the support cross-section decreased approximately twice. This significant change in the proportion of the stiffness of the span and support cross-section can cause the redistribution of bending moments. 
In the second part of the paper, for example of two span elements, it has been estimated the impact of changes in stiffness of the cross-sections on redistribution of bending moments.

As a result of redistribution of bending moments, a slight decrease in the span moments and relatively significant increase in the support moment should be expected. Consequently, the calculated ultimate limit state occurs firstly in cross-section of a support, and then in span cross-section. If omitted the redistribution of bending moments, it would be the reverse situation. ULS would occur firstly in the span cross-section, and then in the support cross-section.

The ultimate limit state in elements with relatively large cross section (as a result of redistribution of bending moments due to changes in stiffness of the cross-section) may occur slightly earlier than could be expected when the impact of redistribution is neglected. In elements with relatively small cross-section, the redistribution of bending moments should not have a significant impact on the time, when ultimate limit state occurs.

\section{References}

[1] A.H. Buchanan, Structural Design for Fire Safety, John Wiley and Sons Ltd., New York, 2002, p. 421.

[2] FIB Bulletin 46, Fire Design of Concrete
Structures-Structural Behavior and Assessment, State-of-art Report, FIB (International Federation for Structural Concrete), July 2008, p. 209.

[3] FIB Bulletin 38, Fire Design for Concrete Structures-Materials, Structures and Modeling, State-of-art Report, FIB (International Federation for Structural Concrete), Apr. 2007, p. 97.

[4] R. Kowalski, P. Król, Experimental examination of residual load bearing capacity of RC beams heated up to high temperature, in: V.K.R. Kodur, J.M. Fransen (Eds.), Sixth International Conference "Structures in Fire", Michigan State University, DEStech Publications Inc., East Lansing, Michigan, USA, 2010, pp. 254-261.

[5] Eurocode 2, Design of Concrete Structures-Part 1-1: General Rules and Rules for Buildings, Ireland, 2004.

[6] Eurocode, Basis of Structural Design EN 1990, Ireland, 2002.

[7] Eurocode 1, Actions on Structures-Part 1-1: General Actions-Densities, Self-Weight, Imposed Loads for Building, Ireland, 2002.

[8] Eurocode 1, Actions on Structures-Part 1-2: General Actions-Actions on Structures Exposed to Fire, Ireland, 2002.

[9] Eurocode 2, Design of Concrete Structures-Part 1-2: General rules-Structural Fire Design, Ireland, 2004.

[10] R. Kowalski, On the Identification of the Reference Isotherm in the Simplified Analysis of R/C Members in Fire, Studies and Researches, Polytechnic University of Milan and Italcementi, Brescia, Italy, 2010, pp. 255-280. (in Italian)

[11] M. Abramowicz, R. Kowalski, Stress-strain relationship of reinforcing steel subjected to tension and high temperature, in: International Conference on Applications of Structural Fire Engineering, Prague, 2009, pp. 134-139. 